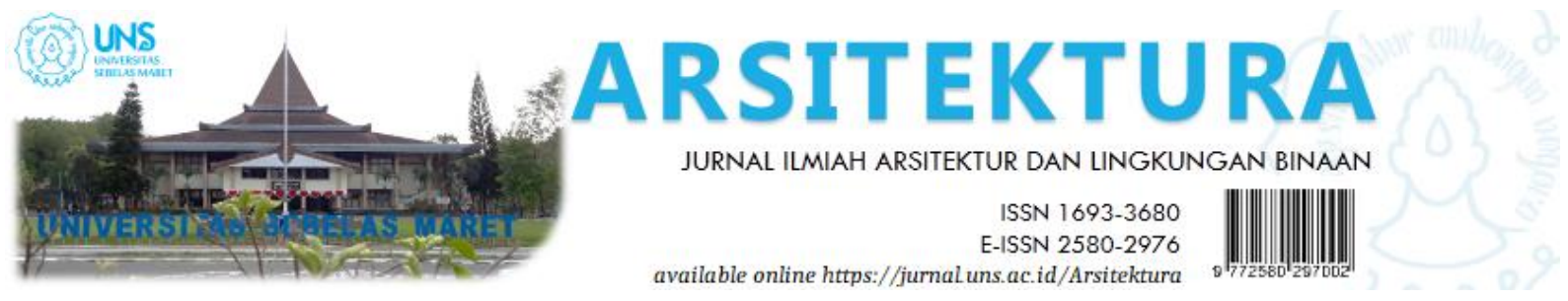

Volume 18 Issue 2 October 2020, pages:185-198

\title{
Kajian Revitalisasi Kawasan Benteng Somba Opu Sebagai Kawasan Bersejarah
}

\section{A Study of Revitalization of Somba Opu Fortress Area as a Historic District}

\author{
M. Maria Sudarwani ${ }^{1 *}$, Sri Pare Eni ${ }^{2}$, M. Mochsen $\mathrm{Sir}^{3}$ \\ Dosen Program Studi Arsitektur, Fakultas Teknik, Universitas Kristen Indonesia 1* \\ margareta.sudarwani@uki.ac.id \\ Guru BesarProgram Studi Arsitektur, Fakultas Teknik, Universitas Kristen Indonesia 2 \\ Doktor Program Studi Magister Teknik Arsitektur, Fa kultas Teknik, Universitas Hasanuddin 3
}

DOI: https://doi.org/10.20961/arst.v18i2.42223

Received: June 19, 2020 Revised: July 12, 2020 Accepted: July 13, 2020 Available online:October 31, 2020

\begin{abstract}
Among a number fortress of Gowa, the largest and strongest is the Somba Opu Fortress. Somba Opu Fortress is the main fortress of the Kingdom of Gowa, the King of Gowa's resident. The uniqueness of the fortress is that it is made of clay and egg whites instead of cement, so tourists are interested in visiting it. The purpose of this research is to contribute the concept of knowledge relating to a study of revitalization of Somba Opu Fortress. In this study the method used is a naturalistic qualitative research with an inductive strategy. Revitalization is a development activity that is aimed to grow back important values of Cultural Heritage with function adjustment new space that is not contrary to principle preservation and cultural value of the community. Zoning system as revitalization methode of Somba Opu Fortress is stillbeing explored by government of Sulawesi Selatan Province. From the research it can be concluded that the Somba Opu Fortress is rectangular. The shape and size of the fortress is the most appropriate condition with the geomorphological conditions at that time. The area of Somba Opu Fortress as a historical district needs to be consideredandwellmaintained by related stakehorders. One of the maintenance efforts that can be done is revitalization to restore the area make it more attractive and mo re useful than before. The fortress of Somba Opu has become historical area, so it should be protected, preserved and maintained so that the culturalmeaning contained in it still remains.
\end{abstract}

Keywords: Fortress Area, Historic District, Revitalization, Somba Opu.

\section{PENDAHULUAN}

Kawasan Benteng Somba Opu terletak kira kira tujuh kilometer ke arah Selatan dari pusat kota Makassar (Indonesia Travel Guides, 1991). Di samping Benteng Somba Opu terdapat benteng pertahanan yang bertebaran di wilayah kawasan inti Kerajaan Gowa antara lain: Benteng Tallo, Benteng Ana Tallo, Benteng Ujung Tana, Benteng Patunuang, Benteng Ujung Pandang, Benteng Bariboso, Benteng Mariso, Benteng Pannakukang, Benteng Garassi, Benteng Galesong, Benteng Sanrobone, Benteng Barombong, Benteng 
Bontorannu, dan Benteng Kale Gowa (M.D., 2012). Di antara sekian banyak benteng kerajaan Gowa tersebut, yang terbesar dan terkuat adalah Benteng Somba Opu dimana benteng ini merupakan tempat kediaman Raja Gowa. Benteng Somba Opu terletak tengah dua muara sungai yaitu Sungai Jeneberang dan Sungai Ballangberu dan dahulu kala berada tepat di tepi Pantai Makassar. Benteng Somba Opu dibangun dalam lima fase, yaitu: 1) Fase Pertama, dimulai pada abad XIV pada masa pemerintahan Raja Gowa IX Daeng Matanre Karaeng Tumapa'risi'Kallonna (1511-1547) pembangunan tembok dari tanah liat mengelilingi Kota Somba Opu; 2) Fase Kedua, masa pemerintahan Raha Karaeng Tuni pallanga Ulaweng (1547-1565) melakukan perkuatan struktur dinding benteng dengan bata dan pendirian dewala serta persenjataan meriam; 3) Fase Ketiga, masa pemerintahan Raja Gowa XII Karaeng Tunijallo (1565-1590) memperkuat dinding bata mengelilingi Kota Somba Opu dan menambahkan sejumlah meriam; 4) Fase Keempat, masa pemerintah an Raja Gowa XIV Sultan Alaudin (1593-1639) dengan perkuatan benteng dengan puluhan meriam; dan 5) Fase Lima, pada masa pemerintahan Sultan Hasanuddin sebagai Raja Gowa XVI (1653-1670) dengan melakukan banyak penyempurnaan dan perkuatan di bagian luar benteng ini (Bullbeck, 1992).

Pada abad ke-16 Benteng Somba Opu merupakan salah satu pelabuhan yang ramai dan sangat penting dalam perdagangan dunia. Kemunculan kekuatan baru di Asia Tenggara yaitu kerajaan Gowa dengan ibukotanya Somba Opu yang berkembang menjadi bandara besar. Hal ini di dukung dengan jatuhnya Malaka ke tangan Portugis tahun 1511 sehingga para pedagang mengalihkan jalur mereka ke ibu kota Somba Opu (Sumantri ed., 2004). Pada waktu itu benteng Somba Opu memberikan fasilitas perbekalan bagi kapal-kapal yang hendak berlayar ke timur maupun ke barat. Rempah-rempah yang dapat diperoleh di pelabuhan Somba Opu kadang-kadang lebih murah daripada di Maluku sendiri. Peranan dan posisi Somba Opu sebagai bandar semakin meningkat pada abad ke-17 (Abduh et.al., 1985). Dewasa ini benteng Somba Opu yang dipercaya terbuat dari batu bata tanah liat dengan perekat putih telur yang unik menjadi daya tarik para wisatawan. Dalam kawasan benteng juga terdapat beberapa rumah adat yaitu Rumah Adat Bugis, Rumah Adat Mandar, Rumah adat Makassar dan Rumah adat Toraja. Rumah adat ini digunakan untuk menampung kegiatan yang melibatkan tiap-tiap kabupaten yang ada di Sulawesi selatan. Biasanya rumah tersebut dilengkapi dengan pameran karya yang berasal dari daerahnya. Kawasan Benteng Somba Opu dalam perkembangannya menjadi pusat budaya (kompleks miniatur budaya) Sulawesi Selatan dimana terdapat semua rumah adat tradisional yang ada di Sulawesi Selatan.

Latar belakang yang lain adalah kondisi Kawasan Benteng Somba Opu sendiri yang sudah mulai tidak terawatt dimana benteng yang terbuat dari batu bata tersebut sudah mulai rusak bahkan ada sebagian besar yang tidak diketahui bentuknya tinggal patok-patok kayu yang ditemui di lokasi sebagai penanda bahwa area dalam batas patok tersebut merupakan bekas benteng. Apabila Kawasan Benteng Somba Opu tidak tertangan dengan baik, dikhawatirkan sisa-sisa benteng yang ada pun ikut rusak dan tidak ada jejak sejarahnya lagi. Berdasarkan latar belakang di atas, maka penelitian ini bermaksud untuk memberikan pemikiran atau kajian terkait revitalisasi. Kawasan Benteng Somba Opu. Menurut Undang-Undang No 11 Tahun 2010 (Pasal 1 angka 31) revitalisasi adalah kegiatan pengembangan yang ditujukan untuk menumbuhkan kembali nilai-nilai penting Cagar Budaya dengan penyesuaian fungsi ruang baru yang tidak bertentangan dengan prinsip pelestarian dan nilai budaya masyarakat. Revitalisasi potensi Situs Cagar Budaya atau Kawasan Cagar Budaya memperhatikan tata ruang, tata letak, fungsi sosial, dan/atau lanskap budaya asli berdasarkan kajian. Revitalisasi dilakukan dengan menata kembali fungsi ruang, nilai budaya, dan penguatan informasi tentang Cagar Budaya (Undang-Undang No 11 Tahun 2010 Pasal 1 angka 80). Revitalisasi merupakan salah satu cakupan kegiatan dalam konservasi. Konservasi adalah segenap proses pengelolaan suatu tempat agar makna kultural yang dikandungnya terpelihara dengan baik. Konservasi dapat meliputi seluruh kegiatan pemeliharaan dan sesuai dengan situasi dan 
kondisi setempat serta dapat pula mencakup Preservasi, Restorasi, Rekonstruksi, Adaptasi dan Revitalisasi (Piagam Burra Charter, 1981). Pendekatan revitalisasi harus mampu mengenali dan memanfaatkan potensi lingkungan (sejarah, makna, keunikan lokasi dan citra tempat) (Danisworo, 2002). Untuk melaksanakan revitalisasi perlu adanya keterlibatan masyarakat. Keterlibatan yang dimaksud bukan sekedar ikut serta untuk mendukung aspek formalitas yang memerlukan adanya partisipasi masyarakat, selain itu masyarakat yang terlibat tidak han ya masyarakat di lingkungan tersebut saja, tetapi masyarakat dalam arti luas (Laretna, 2002). Benteng Somba Opu menarik untuk diangkat sebagai obyek dan lokasi kajian sebagai suatu kajian untuk melakukan revitalisasi dan mempertahankan makna kultural yang ada. Tujuan penelitian ini adalah untuk menggali secara mendalam terkait revitalisasi Kawasan Benteng Somba Opu dan lingkungan permukimannya serta mencermati pola aktivitas masyarakat di sekitar kawasan benteng.

\section{METODE}

Penelitian ini menggunakan pendekatan rasionalistik dengan paradigma kualitatif. Pendekatan penelitian rasionalistik kualitatif ini sesuai dengan sifat masalah penelitian yaitu untuk mengungkap atau memahami konsep pengetahuan yang berkaitan dengan Revitalisasi Kawasan Benteng Somba Opu berdasar landasan berpikir dan dialog pengetahuan. Menurut Cresswell (2010), karakteristik dari pendekatan penelitian kualitatif meliputi beberapa hal yang harus diperhatikan: 1) lingkungan alamiah (natural setting);2) peneliti sebagai instrument kunci (researcher as key holistis); 3) beragam sumber data yang digunakan (multiple sources of data); 4) analisis data induktif (inductive data analysis); 5) makna dari para partisipan (participants meaning); 6) rancangan yang berkembang (emergenz olist); 7) perspektif teoritis (theoritical lens); 8) bersifat penafsiran (interpretive); 9) pandangan menyeluruh (holistis account). Domain penelitian ini adalah arsitektur dengan penggalian data fisik (tangible) dan non fisik. Penelitian dilakukan dengan analisis induktif dan sampel purposif.
Langkah penelitian diawali dengan desk study, dilanjutkan dengan menentukan lokus penelitian yaitu Kawasan Benteng Somba Opu Makassar, menentukan informan kunci, observasi awal kawasan penelitian, menentukan dugaan sementara, observasi lapangan dan menyusun teori lapangan.

\section{HASIL DAN PEMBAHASAN}

Kabupaten Gowa dengan ibukota Sungguminasa termasuk salah satu kabupaten dari 24 kabupaten/kota yang terdapat di Propinsi Sulawesi Selatan. Dengan batas wilayah sebagai berikut: 1) Sebelah Utara berbatasan dengan kota Makassar, Kabupaten Maros dan Kabupaten Bone; 2) Sebelah Timur berbatasan dengan Kabupaten Sinjai, Kabupaten Bulu Kamba, dan Kabupaten Bantaeng; 3) Sebelah Selatan berbatasan dengan Kabupaten Takalar dan Kabupaten Jeneponto; 4) Sebelah Barat berbatasan dengan Kota Makassar dan Kabupaten Takalar. Luas keseluruhan Kabupaten Gowa $1.883 .33 \mathrm{~km}^{2}$, meliputi 18 kecamatan yang terdiri dari 167 desa/kelurahan (Abbas \& Arifah, 2013).

Tabel 1. Lua sa Dah Pembagian Administratif Kabupaten Gowa

\begin{tabular}{clrc}
\hline No & Kecamatan & Luas km & Jml Desa/Kel \\
\hline 1 & Bontonompo & 30,39 & 14 \\
2 & Bontonompo & 29,24 & 9 \\
& Selatan & & \\
3 & Bajeng & 60,09 & 14 \\
4 & Bajeng Barat & 19,04 & 7 \\
5 & Palangga & 48,24 & 16 \\
6 & Barombong & 20,67 & 7 \\
7 & Somba Opu & 28,09 & 14 \\
8 & Bonto Maranmu & 52,63 & 9 \\
9 & Pattallassang & 84,96 & 8 \\
10 & Parangloe & 221,26 & 7 \\
11 & Manuju & 91,90 & 7 \\
12 & Tinggimoncong & 142,87 & 7 \\
13 & Tombolo Pao & 251,82 & 9 \\
14 & Parigi & 132,76 & 5 \\
15 & Bungaya & 175,53 & 7 \\
16 & Bontolempangan & 142,46 & 8 \\
17 & Tompobulu & 132,54 & 8 \\
18 & Biringbulu & 218,84 & 11 \\
\hline & Jumlah/Total & 1.833 .33 & 167 \\
\hline
\end{tabular}

Sumber: Abbas \& Arifin, 2013

Barombong sebagai salah satu kecamatan dari 18 kecamatan di Kabupaten Gowa merupakan wilayah dimana Benteng Somba Opu berada dengan luas wilayah $20,67 \mathrm{~km}^{2}$, terdiri dari 7 
desa/kelurahan termasuk di dalamnya Kelurahan Benteng Somba Opu. Benteng Somba Opu terletak di Jalan Daeng Tata, Kelurahan Benteng Somba Opu, Kecamatan Barombong, Kabupaten Gowa. Jaraknya kurang lebih tujuh kilometer dari arah selatan pusat Kota Makassar. Letak astronomisnya adalah 5' 11'22" LS, 119²4'4” BT dengan ketinggian 0-10 meter (Lihat Gambar 1 pada lampiran).

\subsection{Sejarah Benteng Somba Opu}

Benteng Somba Opu didirikan tahun 1525 oleh Sultan Daeng Matanre Karaeng Tumapa'risi' Kallonna (Raja Gowa IX) dari material tanah liat. Pada waktu pemerintahan Raja Tunipallangga Ulaweng (Raja Gowa XI), Benteng Somba Opu diperkuat dengan penambahan bangunan Bastion dan dilengkapi dengan meriam. Fasilitas Benteng Somba Opu terus ditambah dan diperbaiki hingga Raja Karaeng Tunijallo (Raja Gowa XII) dan diberi batu bata oleh Sultan Alauddin (Raja Gowa XIV), kemudian disempurnakan dan dijadikan benteng induk serta pusat pemerintahan Kerajaan Gowa oleh Sultan Hasanuddin (Raja Gowa XVI).

Kemajuan Makassar sebagai salah satu kota dagang dunia adalah pada masa pemerintahan Sultan Malikussaid (Raja Gowa XV) dan Mangkubumi I Mandacinna Daeng Sitaba Karaeng Pattingalloang (1639-1654). Pada masa pemerintahan beliau, Kerajaan GowaTallo menjadi sebuah kerajaan terkenal dan banyak mengundang perhatian negeri lain untuk datang ke Makassar. Makassar telah berkedudukan sebagai: 1) pusat perniagaan dari pedagang dan pelaut Makassar dan pangkalan bagi persebaran pelayanan niaga mereka; 2) pelabuhan transito terpenting dari komoditas rempah-rempah dan kayu cendana; 3) daerah yang berkelimpahan produksi pangan (beras dan ternak); 4) Bandar Niaga Internasional; dan 5) pemerintah sangat baik dan toleransi (Tika, Rahim, Kasim, \& Sarea, 2013). Dari kelima hal tersebut tercipta hubungan harmonis antara berbagai pihak dalam kegiatan perdagangan dan kehidupan sosial keagamaan.

Pada abad 16-17 Kota Makasar semakin maju dan menjadi salah satu kota dunia yang ramai dikunjungi oleh masyarakat dari berbagai belahan bumi karena memiliki beberapa fasilitas yang berskala internasional seperti Bandar Niaga Internasional di Somba Opu juga memiliki teleskop buatan Galileo.

Tabel 2. Kota besar dunia abad 16-17

\begin{tabular}{clc}
\hline No & Kota Dunia & Jumlah Penduduk \\
\hline 1 & Paris dan napoli & 100.000 orang \\
2 & Malaka & 100.000 orang \\
3 & Banten & 70.000 orang \\
4 & Surabaya & 50.000 orang \\
5 & Gresik & 50.000 orang \\
6 & Makassar & 160.000 orang \\
\hline
\end{tabular}

Sumber: Abidin dalam Tika et.al, 2013

Jumlah penduduknya waktu itu juga cukup banyak dibanding dengan kota-kota besar lainnya. Dari Tabel 2 di atas menunjukkan Makassar pada abad 16-17 sudah menjadi kota besar dunia. Jumlah penduduknya melebihi dari kota Paris juga kota-kota lain di nusantara. Ini menunjukkan perdagangan di kota Makassar saat itu sangat ramai. Pada 1625, sebanyak 22 kapal Portugis mengunjungi pelabuhan setiap tahun. Inggris mendirikan pabrik di Makassar pada 1613, Denmark pada 1618; Pedagang Spanyol dan Cina mulai muncul pada 1615. Pabrik asing itu berlokasi di utara Sombaopu, di tepi seberang Sungai Jenebereng. Makassar terkenal sebagai kerajaan di mata orang asing. Terlepas dari kenyataan bahwa itu adalah negara Islam, ada tempat-tempat ibadah Kristen dan kota ini adalah rumah bagi sejumlah pengungsi terkemuka.

Ketika Makassar menjadi kota dunia, Sultan Malikussaid (Raja Gowa XV) banyak mengijinkan negara lain untuk membuka loji di Somba Opu dan banyak menjalin persahabatan dengan Negaranegara lain di dunia seperti Raja Inggris, Raja Kastilia di Spanyol, Raja Portugis di Lisabon, Raja Muda Portugis di Goa (india), Gubernur Spanyol dan Manchente di Mesoliputan (India), Mufti besar Arab Saudi, dan beberapa kerajaan di nusantara.

Pada tanggal 15 Juni 1669, setelah berbulan-bulan terjadi pertempuran sengit 
antara pasukan Makassar dan BugisBelanda, tentara Belanda berhasil meledakkan celah 20 meter (65 kaki) di dinding Somba Opu setebal 3 meter yang telah didirikan orang Makassar. Keesokan harinya, terjadi pertempuran besar, Belanda menembakkan 30.000 peluru. Pasukan Belanda dan Bugis, banyak yang terserang penyakit disentri dan penyakit tropis lainnnya. Para pejuang Kerajaan Gowa tetap memberikan perlawanan yang gigih atas seragan dan hujan peluru. Jatuh korban yang besar dari kedua belah pihak . Setelah terjadi pertempuran sengit antara Sultan Hasanuddin dengan Belanda dalam perang Makassar, seluruh benteng Somba Opu dikuasai Belanda dan kemudian dihancurkan hingga terendam oleh o mbak pasang pada tanggal 24 Juni 1669 (Nuraeda, Masrury, \& Mokobombang. 2008). Beribu kilo amunisi meledakkan benteng yang tebalnya 12 kaki ini. Istana Somba Opu dibumihanguskan. Kejatuhan Benteng Somba Opu sekaligus merupakan kehancuran Imperium Kerajaan Gowa. Sultan Hasanuddin (Raja Gowa XVI) kalah dalam peperangan. Sultan Hasanuddin mundur ke Benteng Kale Gowa di Maccinik Sombala dan Mangkubumi Karaeng Karunrung meninggalkan istananya di Bontoala kemudian mundur ke Benteng Anak Gowa. Tetapi Belanda mengakui bahwa Perang Makassar merupakan perang yang dahsyat dan terbesar serta memakan waktu paling lama dibanding perang yang dialami Belanda lain di nusantara. Sultan Hasanuddin dan pasukannya dijuluki ayam-ayam Jantan dari Timur karena semangatnya yang pantang mundur. Benteng dan istana Somba Opu diratakan dengan tanah oleh Belanda dengan demikian maka Makassar menjadi pusat pemerintahan dan perdagangan orang-orang Belanda, poros Somba Opu garis Makassar hilang. Ting gallah Makassar memasuki babak sejarah baru dan Somba Opu yang pernah menjadi pusat pemerintahan kerajaan Gowa tinggal menjadi puing-puing (Sumalyo, 2013: 47).

Benteng Somba Opu ditemukan kembali dalam suatu ekskavasi oleh Suaka
Peninggalan Sejarah dan Purbakala tahun 1977-1980 dan ditindaklanjuti dengan adanya Proyek Miniatur Sulawesi Selatan pada tahun 1989-1990. Benteng Somba Opu direkonstruksi pada tahun 1990 agar tidak bertambah rusak dan menjadi sebuah obyek wisata dan sebuah museum bersejarah.

\subsection{Museum Karaeng Pattingaloang}

Menurut Prof. Mr. Dr. H. Andi Zainal Abidin Farid, Museum Karaeng Pattingaloang yang terletak di Kawasan Benteng Somba Opu didirikan pada tahun 1992 untuk melengkapi Taman Miniatur Sulawesi Selatan dan diberi nama Museum Karaeng Pattingalloang, diambil dari nama salah satu tokoh cendekiawan kerajaan Gowa. Karaeng Pattingalloang pernah menjabat sebagai pelaksana raja Tallo, Karena I Mappaijo. Karaeng Pattingalloang adalah Putra Raja Gowa yang kecakapannya melebihi orangorang Bugis Makassar pada umumnya. Karaeng Pattingalloang adalah tokoh cendekiawan dan negarawan Kerajaan Gowa di masa lalu. Menurut Prof. Mr. Dr. H. Andi Zainal Abidin Farid, nama lengkap Karaeng Pattingalloang adalah I Mangadacinna Daeng Sitaba. Beliau adalah putra Malingkang Daeng Manyonri bergelar Karaeng Ketangka karaeng Mattoaya Tumenanga ri agamana bergelar Islam Sultan Abdullah Awwalul Islam dengan jabatan Sultan Alauddin (565-1639) yang diluar negeri dikenal dengan King of Macassar atau El rey De Macassar.

Karaeng Pattingalloang sekalipun merupakan putra raja Tallo I Malingkang Daeng Manyonri dan I wara yang tinggi derajatnya (anak tino) diantara 29 orang saudara-saudara ayahnya ia tidak menjabat Raja tallo, tetapi hanyalah Mangkubumi kerajaan kembar Gowa-Tallo, karena mungkin sekali hendak memusatkan pemikirannya untuk membesarkan Kerajaan Gowa-Tallo. Yang menjadi raja Tallo ialah ayahnya, Sultan Abdullah Awwalul Islam dan kemudian saudara ayahnya bergelar Tummallang ri Timoro. Karaeng pattingalloang tidak pernah bersekolah formal, taman kanak-kanak pun tidak pernah dimasukinya, karena pada zamannya memang 
belum ada sekolah di Makassar. Orang-orang portugis yang disebut oleh Bugis Makassar tuparanggi sudah berdiam di bandar Makassar sejak akhir abad ke-16 karena menganggapnya sebagai Malaka kedua sejak mundurnya Bandar Malaka pada tahun didudukinya oleh bangsa Portugis pada tahun 1511.

Orang-orang Inggris menjadi penduduk Bandar Makassar pada tahun 1615 dan orangorang Denmark pada tahun 1618 yang mendirikan kantor faktori, gudang, rumah, bahkan gereja dan arena Raja Gowa I Manuntungi Daeng Mattola Karaeng Lakiong yang memperoleh gelar Sultan Malikussaid dari Mufti mekka sangat toleran terhadap penganut agama Katolik dan Protestan. Sultan Malikussaid didampingi oleh dua orang cerdik cendekiawan yaitu Karaeng Pattingalloang sebagai mangkubumi dan sekretasinya kerajaan Francisco Mendes sepupu Raja Gowa yang pernah menempuh pendidikan Portugis dan memakai nama Portugis. Oleh karena pergaulannya dengan orang-orang eropa baik yang berdiam di Bandar Makassar maupun yang datang membawa barang dagangan dan didukung oleh kecerdasannya maka Karaeng pattingalloang menguasai banyak bahasa asing. Karaeng Pattingalloang menurut lontarak bilang Gowa-Tallo lahir pada bulan agustusu (agustus) hera 1600, sannak 1009 dan menjadi mangkubumi pada tahun 16391654 mendampingi Raja Gowa Sultan Malikussaid yag memerintah dari tanggal 4 Juni 1639 sampai tanggal 16 november 1653. Penguasaan bahasa asing dan ilmu pengetahuan barat dapat diketahui dari Kerajaan Alexander R Hode (Antony Reyd, 1980:32) yang menulis sebagai berikut: "The High governer of the whale kingdom is called carin pattingalloang whom I found exceedingly wise and sensible a very honest man. He knew mistery very well, had read with curiosity all the chronicles of our European Kings. He always had books of aurs in hand especially those treating with mathematic in which he was quite well versus in dead he had such. A passion for all branches of the science that he worked at it day and night to hear him speak without seeing him one would take him for a native portugese for the speak the language as fluently as people from Lisbon itself' (Pustaka Museum Karaeng Pattingaloang, 2020).

Pemerintah Belanda yang merupakan musuh bebuyutan kerajaan Gowa dalam memperebutkan hegemoni perdagangan di Indonesia merasa kagum juga dan meminta pujangga Nederland Joast Vandel untuk menyusun syair yang akan diukir pada bola dunia (globe) yang terbuat dari tembaga dan akan dihadiahkan kepada karaeng Pattingalloang sebagai penghargaan tertinggi VOC. Adapun kalimat penyair Joast Van Den vandal (Vallentijn 1724:147) yang terukhir pada bola dunia yang berbunyi sebagai berikut: "Dien Aardkllot send't Oostindisch huis, Den Grooten pantagoule't huis, Wiens alddoorsnuffelende brein, een gansche wereld valt te klein". Kalimat itu menyatakan bahwa VOC mempersembahkan bola dunia kepada maha sarjana Karaeng Pattingalloang, yang otaknya selalu menjelajah dunia yang menjadi kecil baginya. Pada bagian lain syair itu tertulis bahwa Karaeng Pattingalloang spark verschilende talen en was zeer bedreven in de latijnse taal, yang artinya dapat berbicara dalam berbagai bahasa asing dan sangat menguasai bahasa latin. Karaeng Pattingalloang adalah seorang ahli hukum dan menguasai beberapa bahasa asing antara lain. Belanda, Denmark, Spanyol dan Cina, dari penghuni kota Makassar (Rosmawati, 2013). Selain itu Karaeng pattingalloang juga memperdalam ilmu falak. Pada tahun 1652 Raja Inggris menghadiahkan Galilean frospective glass, teleskop besar ciptaan astronomi Galileo yang sebenarnya dahulu sudah dipesan untuk dibeli oleh Sultan Alauddin (Raja Gowa XIV) pada tahun 1635. Selain itu Karaeng Pattingalloang juga memiliki perpustakaan lengkap dan koleksi senjata api yang diperolehnya dari sahabatsahabatnya di Eropa termasuk segala karya $\mathrm{Fr}$ Luis de Granada O.P. Ia juga kolektor bukubuku agama Islam dan Kristen, peta dunia, dan buku-buku sains dan teknologi. Ia juga mempelajari teknik dan perahu Galley. Ia mewariskaan sejumlah 1138 perahu galley untuk Kerajaan Gowa lengkap dengan senjata meriam. Patut dicatat bahwa teleskop Galileo pertama pada tahun 1609 dan di Inggris sendiri tidak banyak jumlahnya, akan tetapi Makassar sudah tertarik pada benda aneh itu demi ikut 
berkecimpung dalam ledakan renaissance sains dan teknologi di barat (Pustaka Museum Karaeng Pattingalloang, 2020).

Karaeng Pattingalloang juga seorang pengusaha Internasional. Ia dengan Sultan Malaikussaid berkongsi dengan Pedero De La Mata konsultan dagang Spanyol di Bandar Makasar serta pelaut ulung Portugis bernama Francisco Viera De Figueredo untuk berdagang di dalam negri. Beliau berhasil menjadikan Makassar sebagai entrepot perdagangan kain sutra dan keramik China, kain katun India, kayu cendana Timur, rempah-rempah Maluku dan berlian Borneo (Kalimantan). Beliau juga menjadikan Bandar Makassar yang paling ramai di Asia Tenggara dan paling bersih, cantik dan nyaman di kawasan timur. Joseph Conrad (freya of the seven seas) melukiskan Bandar Makassar sebagai the prettiest and perhaps the clean looking of all the townsof the island (Jordain 1905:294). Jordain melukiskan Bandar Makassar sebagai berikut; Sebelum meninggal dunia pada tanggal 15 September 1654 Karaeng Pattingalloang mahasarjana tanpa gelar dan title doctor menyampaikan pappasang (pesan) kepada orang-orang yang akan ditinggalkannya bahwa ada lima sebab runtuhnya kerajaan besar yaitu1) Punna tenamo naero nipakainga karaeng ma'gauka (apabila kepala Negara yang memerintah tak lagi mau dinasehati atau diperingati); 2) Punna tenamo tumangaseng ri lalang pa'rasanganga (apabila tak ada lagi cendekiawan yang tulus mengabdi di dalam negeri); 3) Punna ngalle ngasengmi' soso' pabbicaranya (jika banyak hakim dan pejabat suka makan suap); 4) Punna majai gau lompoa ri lalang pa'rasanganga (jika terlampau banyak kejadian besar di dalam negeri); dan 5) Punna tenamo kamaseangi atanna karaeng ma'gauka (jika kalau raja yang memerintah tidak lagi menyayangi rakyatnya). Setelah karaeng Pattingalloang meninggal dunia dan dikuburkan dib on to biraeng (Gowa) maka ia diberi gelar kematian tumenanga rib onto biraeng a
(Pustaka Museum Karaeng Pattingalloang, 2020).

\subsection{Kondisi Fisik Benteng Somba Opu}

Benteng Somba Opu terletak di sebuah delta Sungai Jeneberang yang berada di Kecamatan Barombong Kabupaten Gowa.

Benteng Somba Opu dulunya terletak di kampung Sapiria, kelurahan Somba Opu, Kecamatan Palangga, Kabupaten Gowa namun seiring pembangunan serta kebutuhan masyarakat terhadap rekreasi kota maka jalan masuk ke Benteng Somba Opu dibangun dan terletak di Jalan Daeng Tata Kota Makassar Provinsi Sulawesi Selatan. Berdasarkan hasil pemetaan tahun 1986 Suaka Peninggalan Sejarah dan Purbakala Provinsi Sulawesi Selatan luas benteng Somba Opu $113.590 \mathrm{~m} 2$ dengan posisi geografis pada $051136 \mathrm{LS}$ dan $1192410 \mathrm{BT}$.

Kondisi fisik Benteng Somba Opu berbentuk empat persegi, sebuah sisinya berukuran kurang lebih $2 \mathrm{~km}$ dengan tinggi tembok 7-8 meter. Ketebalan dinding rata-rata $360 \mathrm{~cm}$ diperkuat dengan 4 Bastion dan luasnya sekitar 1500 hektar. Ada tiga bastion yang masih terlihat sisa-sisanya, yaitu bastion di sebelah barat daya, bastion tengah, dan bastion barat laut. Yang terakhir ini disebut Buluwara Agung. Di bastion inilah pernah ditempatkan sebuah meriam paling dahsyat yang dimiliki orang Indonesia. Namanya Meriam Anak Makassar. Bobotnya mencapai $9.500 \mathrm{~kg}$, dengan panjang 9 meter, dan diameter $4,14 \mathrm{~cm}$ (Medanbisnisdaily, 2014). Setelah tertimbun selama kurang lebih 3 abad, dalam upaya menyingkap kembali kejayaan dan kebesaran Kota Somba Opu, telah dilaksanakan kegiatan penelitian dan pemugaran yang sampai saat ini masih terus dilakukan oleh Suaka Peninggalan Sejarah dan Purbakala Provinsi Sulawesi Selatan. Kini status Benteng Somba Opu telah dijadikan sebagai salah satu kawasan wisata yang dikenal dengan nama Miniatur Sulawesi Selatan. Di kawasan ini dibangun pula rumah-rumah adat dari berbagai etnis yang ada di Sulawesi Selatan. Sebagai representasidaerah-daerah Kabupaten/Kota di Wilayah Sulawesi Selatan. Bangunan-bangunan tersebut terutama berfungsi sebagai sarana penunjang kegiatan- 
kegiatan yang berskala provinsi (lihat Gambar 2). Di dalam benteng juga terdapat sebuah meriam bernama "Baluwara Agung" sepanjang 9 meter dengan berat $9.500 \mathrm{~kg}$, dan sebuah museum yang berisi benda-benda bersejarah peninggalan Kesultanan Gowa (Nuraeda, Masrury, \& Mokobombang. 2008).

Dari Gambar 2 Gambar situasi kondisi eksisting Kawasan Benteng Somba Opu (lihat pada lampiran artikel) terlihat kawasan Somba Opu terdiri dari bagian dinding benteng yang masih ada, bastion, Istana Maccini Sombala, terdapat panggung terbuka, rumah adat Gowa, rumah adat Ujung Pandang (Makassar), rumah adat Mamuju, rumah adat Majene, rumah adat Mandar, rumah adat Kajang, rumah adat Bugis, rumah adat Tator, rumah adat Luwu, rumah adat Bulukumba, rumah adat Soppeng, Baruga (Lihat Gambar 3), Museum Karaeng Pattingalloang, Taman Situs dan pintu utama. Bangunan-bangunan tersebut di atas merupakan bangunan yang berada di Zona Inti. Sangat disayangkan untuk area A, B, C, D, E, F, G Kawasan Benteng Somba Opu rencana akan difungsikan oleh investor sebagai Gowa Discovery Park yang bisa dilihat pada Gambar 4 (meskipun hal ini masih akan dikaji kembali oleh pemerintah terkait). Sedangkan Area H, I, J, K, L, M, N, O, P, Q, R. S merupakan kawasan Benteng Somba Opu yang diprediksi berbentuk persegi.

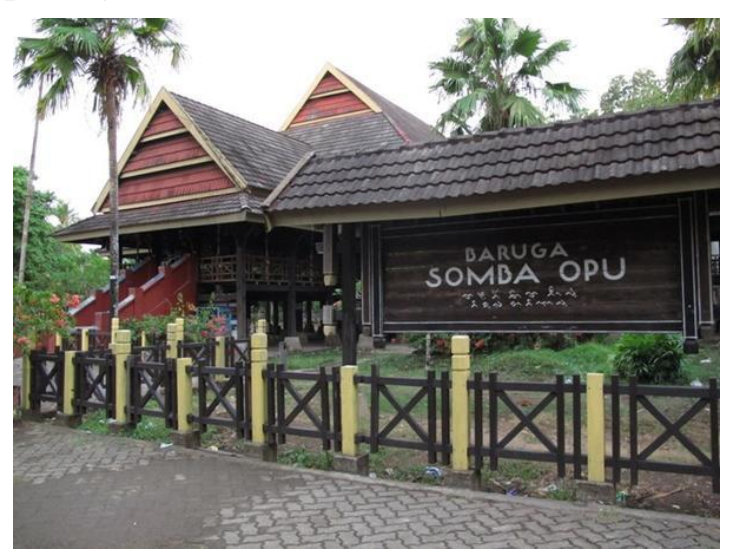

Gambar 3. Baruga Somba Opu (Dokumentasi Pribadi, 2020)

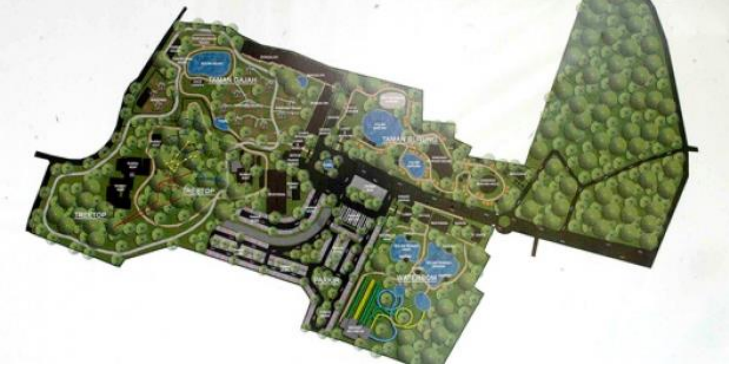

Gambar 4. Rencana Gowa Discovery Park (nasional.tempo.co, 2020)

Bentuk Benteng Somba Opu secara arkeolog is belum diketahui dikarenakan sebagian dindingnya terutama dinding bagian utara belum teridentifikasi. Beberapa ekskavakasi sudah dilakukan dalam rangka mengetahui keberadaan dinding tersebut. Tetapi ada sebuah peta tahun 1658 yang merupakan hasil stilasi Francois Valentijn dan disempurnakan lagi oleh Bleau yang memberikan informasi penting tentang kondisi benteng. Dari Gambar 5 (lihat pada lampiran artikel) Sketsa Benteng Somba Opu tahun 1658 (Sumber: Bakorsutanal, 1991) dan Gambar 6. Foto Sketsa Benteng Somba Opu di Museum Karaeng Pattingalloang diperoleh data bahwa benteng somba opu berbentuk persegi empat. Dalam kawasan benteng terletak istana raja, istana kediaman raja, gudang kerajaan, masjid kerajaan yang dikelilingi oleh tembok pagar tinggi dan tebal serta difasilitasi dengan persenjataan. Istana kediaman raja berlokasi di sebelah selatan dari benteng, sedangkan istana raja dan gudang kerajaan terletak kira-kira hampir di tengah kawasan agak ke sebelah selatan. Masjid terletak di sebelah timur dari istara raja. Tiap bangunan masing-masig memiliki halaman dan dikelilingi pagar kecil. Di bagian luar benteng terletak perusahaan orang Portugis, perusahaan orang Gujarat, kediaman Antonio Da Costa, los pedagang Belanda yang dibuka tahun 1607, los pedagang Inggris yang dibuka tahun 1613, los pedag ang Spanyol yang dibuka tahun 1615, los pedagang Cina dan Denmark yang dibuka tahun 1618, sungai di bagian timur benteng, sungai di bagian barat benteng. Di sebelah barat laut terletak bekas Istana Maccini Sombala dengan dinding yang sangat tebal. Dari tempat inilah Raja memantau para pedagang, lalu lintas kapal, arus bongkar muat barang, dan penarikan bea masuk pelabuhan. 


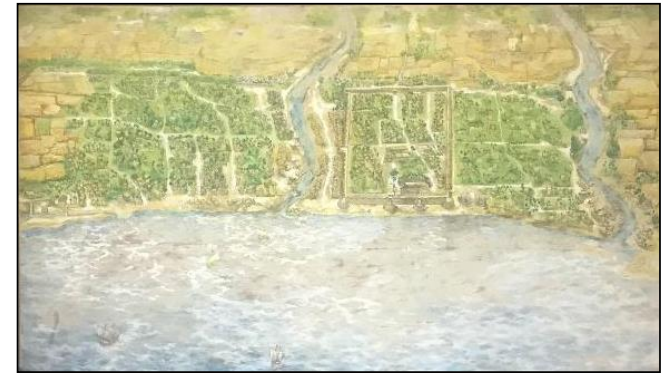

Gambar 6. Foto Sketsa Benteng Somba Opu Tahun 1658 diMuseum Karaeng Pa ttingalloang (Dokumentasi Pribadi, 2020)

\subsection{Sturktur Benteng Somba Opu}

Menurut ilmuwan Inggris, William Wallace, benteng Somba Opu merupakan benteng terkuat yang pernah dibangun orang nusantara, terlihat apabila kita memasuki kawasan benteng omba Opu yang memiliki tembok benteng cukup kokoh yang memnggambarkan sistem pertahanan yang sempurna pada zamannya yang amat sulit ditemus dan diruntuhkan (Lihat Gambar 7).

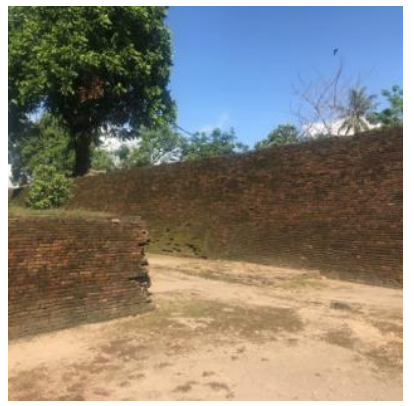

Gambar 7. Dinding Benteng Somba Opu yang kokoh

Struktur pembentuk benteng terbuat dari batu bata merah dengan berbagai ukuran. Ketebalan dinding benteng yaitu $200-300 \mathrm{~cm}$ pada sisi Timur dan Selatan, dan 300-400 cm di sisi Barat.

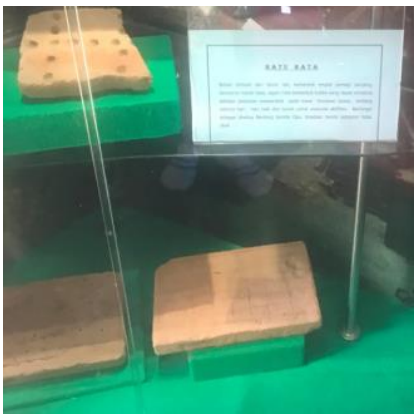

Gambar 8. Batu bata Benteng Somba Opu tersimpandi Museum
Bahan batu bata terbuat dari tanah liat berbentuk empat persegi panjang berwarna merah bata dan putih telur sebagai pengganti semen., ragam hias berbentuk ketika yang dapat dimaknai sebagai pedoman masyarakat pada masa Kerajaan Gowa, tentang adanya hari-hari baik dan buruk untuk memulai aktivitas. Berfungsi sebagai dinding Benteng Somba Opu. Batu bata yang terdapat motif berupa stempel jari tangan, motif yang ditungkan pada batu bata ini dapat dimaknai sebagai simbol penolak bala (bahaya) dan biasanya diletakkan pada pintu gerbang masuk benteng.

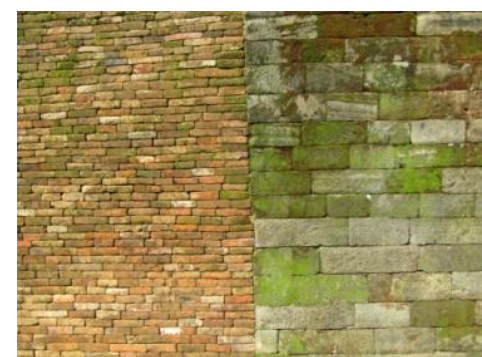

Gambar 9. Variasi Batu bata Benteng Somba Opu (Dokumentasi Priba di, 2020)

Menurut Suaka Peninggalan Sejarah dan Purbakala Sulsel (1987), temuan batu bata di lokasi situs diklasifikasikan sebagai berikut: 1) tipe I panjang $25 / 27 \mathrm{~cm}$ lebar $14 / 15 \mathrm{~cm}$, tebal $4 / 4.5 \mathrm{~cm}$; 2) tipe II panjang $20 / 22 \mathrm{~cm}$ lebar 8 $10 \mathrm{~cm}$, tebal $3 / 3.5 \mathrm{~cm} ; 3)$ tipe III panjang $14 / 15 \mathrm{~cm}$ lebar $5 / 6 \mathrm{~cm}$, tebal $3 / 4 \mathrm{~cm}$; 3 ) tipe IV panjang $8-12 \mathrm{~cm}$ lebar $3.4 \mathrm{~cm}$, tebal $3 \mathrm{~cm}$.

Pada saat peneliti menelusuri kondisi eksisting benteng Somba Opu di bulan Januari 2020 beberapa bagian terdapat patok-patok beton yang memberi tanda bahwa di bawahnya terdapat dinding yang belum tergali (Lihat Gambar 10).

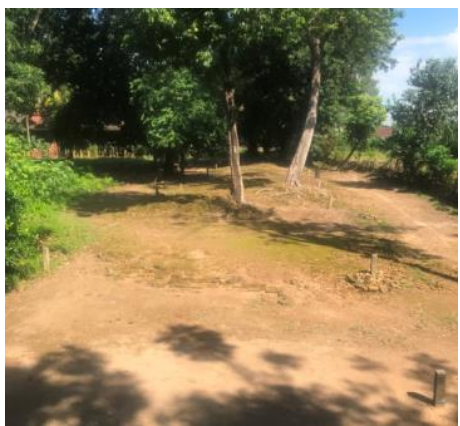

Gambar 10. Menelusuri pa tok batas Benteng Somba Opu

(Dokumentasi Priba di, 2020) 


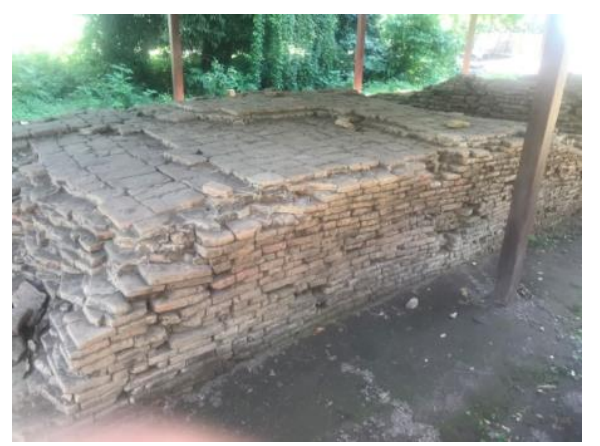

Gambar 11. Kondisi dinding Benteng Somba Opu yangtersisa

(Dokumentasi Pribadi, 2020)

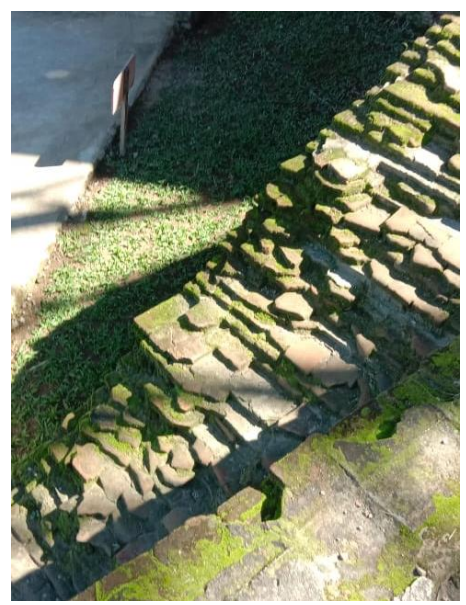

Gambar 12. Tumpukan batu bata benteng Somba $\mathrm{Opu}$

(DokumentasiPribadi, 2020)
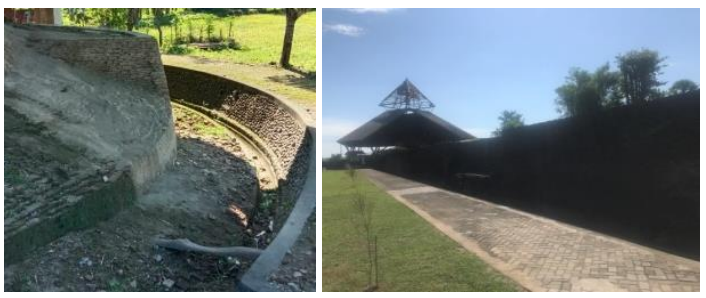

Gambar 13. Sisa-sisa Bastion Benteng (Dokumentasi Pribadi, 2020)

\subsection{Kehidupan Sosial Budaya}

Penduduk Kabupaten Gowa khususnya penduduk Desa Benteng Somba Opu didominasi suku Makassar. Sistem social masyarakat dalam kehidupan sehari-hari terikat oleh system norma atau aturan adat yang dianggap luhur dan sacral yang disebut pangngadakkang. Pangngdakkang yaitu ideide atau norma yang membuahkan hasil dari tingkah laku manusia tersebut baik berupa materiil maupun non materiil. Pangngadakkang dilatarbelakangi konsep siri' dan pace. Siri' bagi orang Makassar merupakan nilai yang paling hakiki yang disimbolkan sebagai martabat dan harga diri manusia, sedang pace adalah rasa solidaritas yang tinggi. Sistem kekerabatan pada masyarakat Makassar disebut dengan istilah bija pammanakang yang artinya ikatan kekerabatan yang sangat erat yang terbentuk karena ada pertalian darah. Sistem kekerabatan umumnya menganut prinsip yang bersifat bilateral dan parental, artinya disamping mengikuti garis keturunan ayah juga mengikuti garis keturunan ibu. Ini menunjukkan bahwa garis keturunan keluargamasyarakat Makassar sangat luas dan kadang menimbulkan suatu ikatan kekeluargaan dalam masyarakat. Oleh karena itu setiap penduduk selalu menganggap dirinya menjadi bagain dari penduduk sekampungnya. Masalah perkawinan selalu menjadi masalah segenap keluarga. Oleh karena itu pemilihan jodoh bagi anak-anak mereka sangat dipertimbangkan, dimana yang akan menjadi pasangan bagi anak mereka harus sepadan dan serasi dengan kedudukan sosial mereka. Hal ini disebut dengan kasiratang. Bagi orang Makassar perkawinan tujuannya tidak hanya untuk memenuhi kebutuhan biologis saja, melainkan juga untuk menaikkan gengsi social bagi salah satu atau kedua pasangan tersebut. Pada masa lalu untuk menjaga status dalam masyarakat, orang Makassar sangat memperhatikan status yang diperoleh melalui keturunan. Stratifikasi sosial dalam masyarakat Makassar diklasifikasikan dalam tiga bagaian yaitu: 1) Karaeng atau golongan bangsawan; 2) To Baji atau golongan To Maradeka (orang merdeka); 3) Golongan Ata (Sahaya) (Abbas \& Arifah, 2013).

\subsection{Kajian Revitalisasi Benteng Somba Opu}

Revitalisasi Benteng Somba Opu sudah mendapatkan perhatian dari Dinas Kebudayaan dan Pariwisata Provinsi Sulawesi Selatan. Upaya revitalisasi ini sejalan dengan Undang-undang Republik Indonesia Nomor 11 Tahun 2010 Tentang Cagar Budaya. Menurut 
Undang-undang Republik Indonesia Nomor 11 Tahun 2010 yang dimaksud cagar budaya adalah warisan budaya bersifat kebendaan berupa benda cagar budaya, bangunan cagar budaya, struktur cagar budaya, situs cagar budaya, dan kawasan cagar budaya di darat dan/atau di air yang perlu dilestarikan keberadaannya karena memiliki nilai penting bagi sejarah, ilmu pengetahuan, pendidikan, agama, dan/atau kebudayaan melalui proses penetapan (Pasal 1 angka1). Kegiatan Zonasi Kawasan Benteng Somba Opu telah dilakukan tahun 2019 dalam rangka melaksanakan Undang-Undang No 11 Tahun 2010 dan juga dalam upaya persiapan kegiatan revitalisasi Kawasan Wisata Benteng Somba Opu yang merupakan salah satu program prioritas Gubernur Sulawesi Selatan tentang Kepariwisataan. Usaha kegiatan zonasi ini bertujuan untuk menguatkan dan meningkatkan citra Kawasan Benteng Somba Opu sebagai kawasan Cagar Budaya yang bernilai tinggi yang mampu mengangkat harkat dan martabat bangsa Indonesia sesuai dengan tujuan pelestarian Cagar Budaya yang diamanatkan Undang-Undang Nomor 11 Tahun 2010 Pasal 3. Kegiatan Zonasi Kawasan Benteng Somba Opu mengacu pada UndangUndang No 11 Tahun 2010 Pasal 72-74 sedangkan pendaftaran Benteng Somba Opu sebagai Situs Cagar Budaya telah dilakukan pada bulan Desember tahun 2014. Sistem Zonasi 2019 membagi Kawasan Benteng Somba Opu menjadi empat Zona yaitu: 1) Zona Inti, merupakan area perlindungan utama untuk menjaga bagian terpenting Cagar Budaya; 2) Zona Penyangga, merupakan area yang melindungi zona inti; 3) Zona Pengembangan, merupakan area peruntukan pengembangan potensi cagar budaya bagi kepentingan rekreasi, konservasi lingkungan alam, lanskap budaya, kehidupan budaya tradisional, keagamaan dan kepariwisataan; dan 4) Zona Penunjang, merupakan area peruntukan bagi sarana dan prasarana penunjang serta untuk kegiatan komersil dan rekreasi umum.

Kawasan bersejarah Somba Opu telah menjadi bukti perjalanan serta peristiwa bersejarah, antara lain: Benteng Somba Opu dibangun sendiri oleh anak bangsa dalam rangka melindungi keberadaan Kerajaan Gowa, kegigihan perjuangan anak bangsa dalam mempertahankan Benteng Somba Opu terhadap serangan penjajah, Benteng Somba Opu merupakan pusat pemerintahan dan pelabuhan rempah-rempah yang ramai dikunjungi pedagang asing dari Asia dan Eropa pada pertengahan abad ke-16, benteng ini menjadi salah satu benteng terkuat yang dimiliki oleh masyarakat Indonesia, sehingga sudah seharusnya jika kawasan bersejarah ini dilindungi, dilestarikan dan dijaga keberadaannya agar tetap hidup sepanjang masa. Nilai Penting Ilmu Pengetahuan. Benteng Somba Opu terbukti telah menumbuhkan minat bagi para ahli. Minat ini ditunjukkan dari sejumlah penelitian yang sudah dilakukan oleh peneliti dari dalam maupun luar negeri. Sejumlah tulisan ilmiah yang telah dihasilkan, diterbitkan, dan dibahas dalam berbagai forum ilmu pengetahuan di tingkat nasional dan internasional (Rustan, Iswadi dan Supriadi, 2013).

\section{KESIMPULAN}

Dalam hubungannya dengan situs Benteng Somba Opu, letak dan lokasi pendirian benteng dipengaruhi oleh morfologi setempat dimana masyarakat umum secara naluriah dapat memilih lokasi strategis benteng pada masa itu. Benteng Somba Opu didirikan pada tempat yang paling sesuai di sebuah delta sungai jeneberang, meskipun demikian tidak terpikirkan bahwa sendimentasi sungai cukup kuat dan pendangkalan laut cukup cepat berlangsung. Secara arkeologis bentuk benteng memang belum diketahui karena sebagian dindingnya belum teridentifikasi, terutama dinding sebelah utara, tetapi berdasarkan analisa sketsa kuno sebagai bahan acuan, Benteng Somba Opu berbentuk persegi panjang. Kondisi eksisting benteng Somba Opu yang belum diketahui perlu dilakukan adanya rekonstruksi dengan mengembalikan bangunan benteng semirip mungkin dengan aslinya dengan menggunakan material / bahan baru yang telah diteliti dan dinilai tepat untuk menggantikan material yang lama yang sudah tidak mungkin dipakai kembali. Hal ini bisa diawali dengan membuat hasil rekonstruksi miniatur Benteng Somba Opu. 
Kegiatan Zonasi yang telah dilakukan pada prinsipnya sangat bermanfaat karena sesuai dengan Undang-Undang No 11 Tahun 2010 Pasal 72-74. Kegiatan ini perlu dilanjutkan dengan memberikan fokus terhadap bangunanbangunan di sekitar benteng yang merupakan kawasan di Zona Inti yang merupakan kawasan perlindungan supaya tidak dimanfaatkan untuk hal lain. Bangunanbangunan di Zona Inti sebaiknya dilakukan rehabilitasi berupa perbaikan dan pengembalian kondisi bangunan yang rusak atau menurun dengan tetap menjaga nilai historisnya sehingga dapat berfungsi kembali. Dari penelusuran dapat disimpulkan bahwa kawasan Benteng somba Opu sebagai peninggalan bersejarah saat ini perlu diperhatikan dan dipelihara dengan baik oleh pihak-pihak terkait. Salah satu upaya pemeliharaan yang dapat dilakukan yakni revitalisasi dengan disertai rekonstruksi dan rehabilitasi yang mengacu pada kegiatan zonasi yang ada. Dengan upaya tersebut diharapkan dapat mengembalikan benteng Somba Opu ke bentuk semula dan agar Kawasan Benteng Somba Opu dapat menjadi obyek wisata bersejarah sehingga lebih menarik dan bermanfaat lebih dari yang ada sebelumnya. Kawasan bersejarah merupakan salah satu aset penting yang dimiliki oleh suatu daerah. Kawasan bersejarah Somba Opu telah menjadi bukti perjalanan serta peristiwa bersejarah, sehingga sudah seharusnya jika kawasan bersejarah ini dilindungi, dilestarikan dan dijaga keadaanya agar makna kultural yang terkandung didalamnya tetap hidup sepanjang masa.

\section{REFERENSI}

Abbas, Abbas \& Sarifah, ST. 2013. Benteng Somba Opu Sulawesi Selatan. Makassar: Dinas Kebudayaan dan Kepariwisataan Propinsi Sulawesi Selatan.

Abduh, M., Pawiloy, S., Masduki, M., Baso, M.N., \& Abidin, Z. 1985. Sejarah Perlawanan Terhadap Imperialisme dan Kolonialisme di Sulawesi Selatan. Jakarta: Depdikbud.

Badan Koordinasi Survey dan penataan Nasional (Bakorsurtanal). 1991. Laporan kegiatan Penentuan Batas Wilayah Cagar
Budaya Dalam rangka Penyelamatan Situs benteng Somba Opu.

Bulbeck, David. 1992. Rekonstruksi Makasar dan Benteng-Bentengnya. Makassar: Hasanuddin University Press.

Bulbeck, David \& Hakim, Budianto. 2005. The Human Fossil Cranium From Leang Batu Tunpa, Selayar, Sulawesi Selatan. Makassar: Hasanuddin University Press.

Cresswell, J. W. 2010. Research Design: Qualitatif, Quantitative, and Mixed Methods Approach. California: Sage Publication.

Danisworo, M. 2002. Revitalisasi Kawasan Kota, Sebuah Catatan dalam, Pengembangan dan Pemanfaatan Kawasan Kota dalam Newsletter URDI (Urban and Regional Development Institute, vol. 13 Januari-Maret

Laretna, Adhisakti T. 2002. Peran LembagaLembaga Yang Menangani Obyek Budaya Sebagai Aset Pariwisata. Jakarta. http://perencanaankota.blogspot.com.201 2.

M.D., Sagimun. 2012. Benteng Ujung Pandang. Jakarta: Depdikbud.

Medanbisnisdaily. 2014. Berkunjung ke Situs Benteng Somba Opu, Makassar. (http://www.medanbisnisdaily.com/news/ $\mathrm{read} / 2014 / 01 / 19 / 73898 / \mathrm{ber}$ kunjung-kesitus-benteng-somba-opu-makassar/) Diakses pada tanggal 19 Juni 2020.

Moleong, Lexy J. 2010. Metodologi Penelitian Kualitatif. Bandung: PT Remaja Rosdakarya.

Mulyanto, Agus. 2009. Sistem Informasi Konsep dan Aplikasi. Yogyakarta. Pustaka Pelajar.

Nuraeda, Masrury, \& Mokobombang. 2008. Album Sejarah dan Kepurbakalaan Sulawesi Selatan (Wisata Kultural, Historis). Dinas Kebudayaan dan Pariwisata Propinsi Sulawesi Selatan.

Parinding, Samban C. \& Achjadi, Judi. 1988. Toraja: Indonesia's Mountain Eden. Singapore: Times Editions.

Rosmawati. 2013. Perkembangan Tamadun Islam di Sulawesi Selatan, Indonesia dari Perspektif Arkeologi dan Sejarah. Tesis Universitas Sains Malaysia.

Rustan, Iswadi danSupriadi, 2013. Konservasi dan Zonasi Benteng Somba Opu. Dari Kale Gowa ke Somba Opu, Merajut 
Simpu-simpul Pertahanan Kerajaan Gowa di Sulawesi Selatan. Makassar: Balai Pelestarian Cagar Budaya Makassar.

Soekanto, Soejono. 1990. Sosiologi Suatu Pengantar. Jakarta.PT Raja Grafindo Persada.

Suaka Peninggalan Sejarah dan Purbakala Sulawesi Selatan. 1987. Laporan Penggalian Penyelamatan Benteng Somba Opu. Ujung Pandang: Suaka Peninggalan Sejarah dan Purbakala Sulawesi Selatan.

Sumalyo, Yulianto. 2013. Arsitektur, Konstruksi dan Pola Pemukiman dalam Benten. Dari Kale Gowa ke Somba Opu: Merajut Simpul-simpul Pertahanan Kerajaan Gowa di Sulawesi Selatan. Makassar: Balai Pelestarian Cagar Budaya Makassar.

Sumantri., ed. 2004. Kepingan Mozaik Sejarah Budaya Sulawesi Selatan. Ininnawa

Swasono, Sri Edi. 2002. Bung Hatta Bapak Kedaulatan Rakyat: Memperingati Satu Abad Bung Hatta. Jakarta: Yayasan Hatta.

Tika, Rahim, Kasim, \& Sarea. 2013. Makassar Tempo Doeloe. Lembaga Kajian dan Penelitian Sejarah Budaya Sulawesi Selatan.

Undang-Undang Republik Indonesia No. 11 Tahun 2010 Tentang Cagar Budaya.

Zielenbach, Sean. 2000. The Art of Revitalization: Improving Conditions in Distressed Inner-City Neighborhoods. New York: Garland Publishing Inch.

\section{LAMPIRAN}

Gambar 1.Gambar Peta Wilayah Administrasi Kabupaten Gowa

Gambar 2.Gambar Situasi kondisi eksisting kawasan Benteng Somba Opu Gambar 5. Sketsa Benteng Somba Opu Tahun 1658 


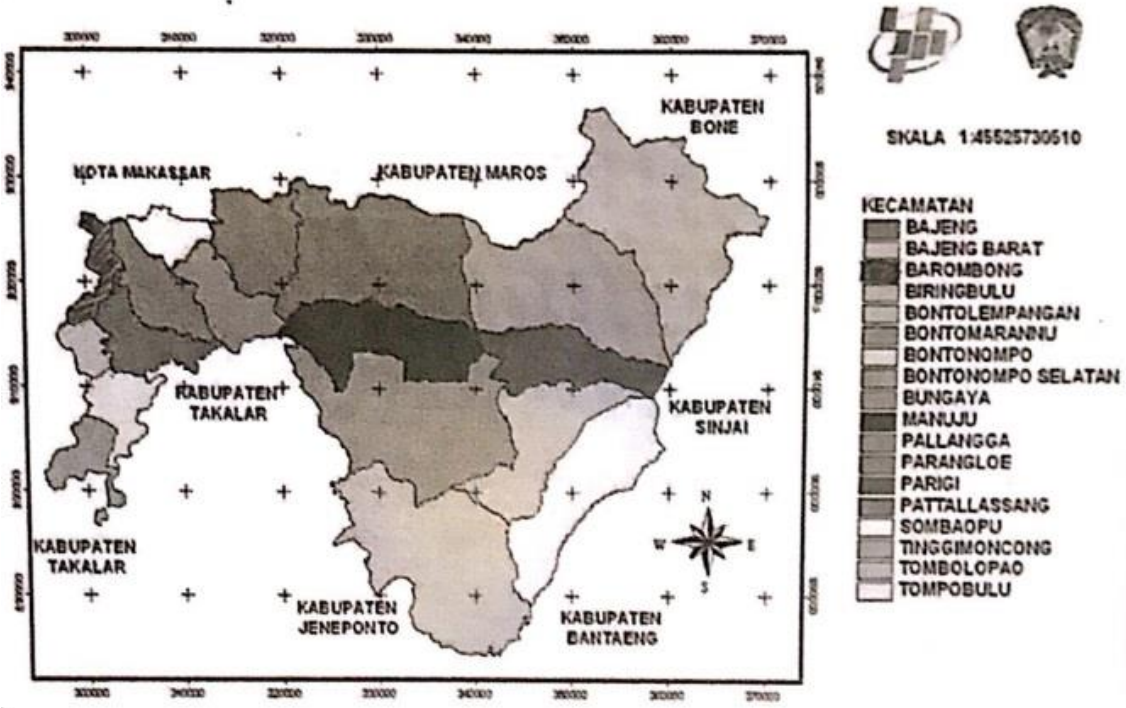

Gambar 1. Gambar Peta Wilayah Administrasi Kabupaten Gowa (sumber: Abbas \& Arifin, 2013)

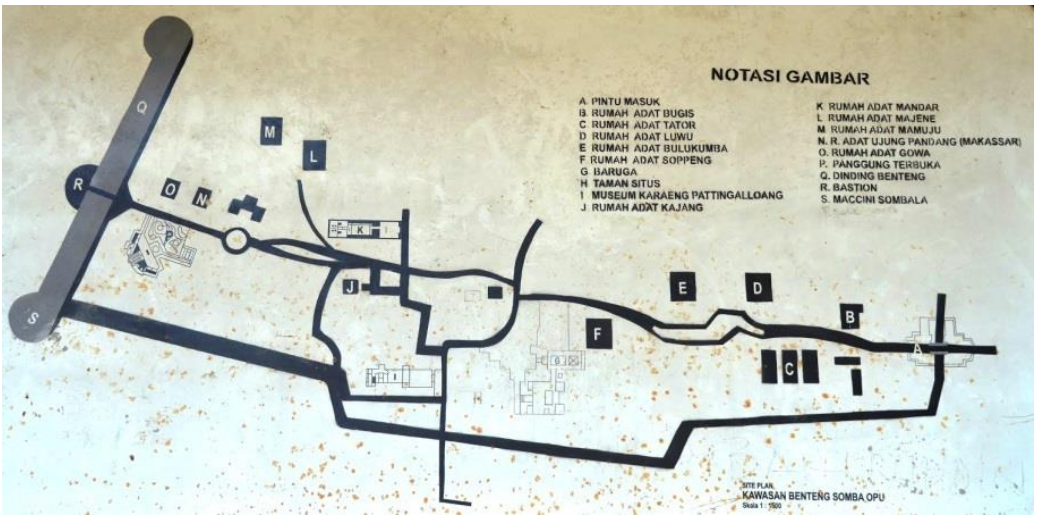

Gambar 2. . Gambar Situasi kondisi eksisting kawasan Benteng Somba Opu (RTBL, 2016)

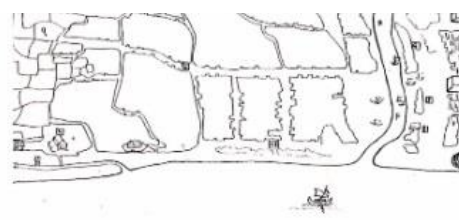

34

A : Doerah Benteng Somba Opu

B. Istana Raja

C : Istana kediaman Raja

D : Gudang Kerajaan

E. Mesjid Kerajaan

$F$, Peruschaanorang Portugis

G, Perusohoan or ahg Gujarat

$\mathrm{H}$ : Perchu perahu Kerajaan

1. Kediaman Antonio da Costa

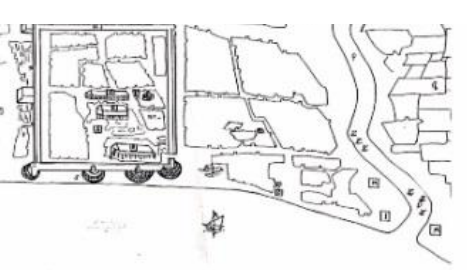

$\sqrt{5}$

$K$, Los pedagang Denemark

$\mathrm{L}$. Tempat pedagang Inggeris

$M$. Pasar besar

$\mathrm{N}$. Bagian utara kota

O. Pasar baru

P. Sungai yang Japat dilayari

Q. Lapangan dan sawah

IR. Sungai bagian utara kota

S : Kota Somba Opu

Gambar 5. Sketsa Benteng Somba Opu Tahun 1658

(Sumber: Bakorsutanal, 1991) 